\title{
ATIVIDADE DE PROGRAMAÇÃO COM CRIANÇAS DE 4-6 ANOS: A CONSTRUÇÃO DA NOÇÃO DE ALGORITMO
}

\author{
Cristiane Pelisolli Cabral ${ }^{1}$ \\ Rosane Aragón ${ }^{2}$ \\ Alexandre da Silva Simões ${ }^{3}$ \\ ${ }^{1}$ PPGEDU/UFRGS - pelisolli@gmail.com \\ https://orcid.org/0000-0003-4002-6363 \\ ${ }^{2}$ PPGEDU/PPGIE/UFRGS - rosane.aragon@ ufrgs.br \\ https://orcid.org/0000-0002-0307-4457 \\ ${ }^{3}$ PGEE/UNESP-Sorocaba - alexandre.simoes@unesp.br \\ https://orcid.org/0000-0002-1457-6305
}

\begin{abstract}
Resumo:
O presente estudo está vinculado a uma pesquisa que objetiva investigar o processo de construção da noção de algoritmo na atividade de programação realizada por crianças de 4 até 12 anos de idade. Apresentamos, aqui, os resultados obtidos através da análise de entrevistas realizadas com sete sujeitos de 4 até 6 anos de idade. Na primeira etapa da entrevista, foram realizadas provas cognitivas, baseadas no método clínico-piagetiano para a verificação do estádio de desenvolvimento intelectual de cada sujeito e o desenvolvimento de noções tais como classificação, seriação, objeto, causalidade e espaço. Na segunda etapa, os sujeitos resolveram problemas para fazer movimentar um robô. A entrevista foi gravada em vídeo e analisada com auxílio do software de análise qualitativa MAXQDA2020®. Como conclusões, podemos indicar relações entre o desenvolvimento de noções como classificação, seriação, objeto, causalidade e espaço e o êxito na resolução de problemas envolvendo a construção de algoritmos para a programação de um robô.
\end{abstract}

Palavras-chave: Desenvolvimento Cognitivo; Atividade de Programação; Epistemologia Genética; Robótica Educacional.

\section{PROGRAMMING ACTIVITY WITH CHILDREN 4-6 YEARS OLD: BUILDING THE NOTION OF ALGORITHM}

\begin{abstract}
:
This study is linked to a research that investigates the process of constructing the notion of algorithm in the programming activity performed by children from 4 to 12 years of age. Here, we present the results obtained through the analysis of interviews carried out with seven subjects from 4 to 6 years of age. In the first stage of the interview, cognitive tests were carried out, based on the clinical-Piagetian method to verify the stage of the intellectual development of each subject and the development of notions such as classification, seriation, object, causality, and space. In the second stage, the subjects solved problems to make a robot move. The interview was videotaped and analyzed using the MAXQDA2020® qualitative analysis software. As conclusions, we can indicate relationships between the development of notions such as classification, seriation, object, causality, and space and the success in solving problems involving the construction of algorithms for programming a robot.
\end{abstract}

Keywords: Cognitive Development; Programming Activity; Genetic Epistemology; Educational Robotics. 


\section{Introdução}

A análise do percurso cognitivo de resolução de problemas em robótica educacional sob enfoque da macro e da microgênese (Cabral, 2010) evidencia, de maneira geral, as relações entre os processos cognitivos e essa atividade tecnológica. Agora, é necessário focar mais especificamente a atividade de programação, pois parte-se da hipótese de que, quando a criança está programando um computador ou um robô, existe um percurso cognitivo que faz com que o sujeito consiga transformar a linguagem humana em linguagem de programação. Por esse motivo, está sendo realizada uma pesquisa que tem como objetivo investigar a psicogênese, ou seja, os processos cognitivos de crianças de 4 aos 12 anos envolvidos na construção do algoritmo para fazer movimentar um robô concreto sem a utilização de software de programação na tela de um computador. O estudo que, por ora, trazemos aqui é parte dessa pesquisa. Apresentaremos alguns resultados obtidos a partir das análises das entrevistas realizadas com sujeitos de 4-6 anos de idade.

Piaget (1980) nos diz que o problema central do desenvolvimento é compreender a formação, a elaboração, a organização e o funcionamento das estruturas cognitivas. Assim, através da interpretação da relação entre sujeito e objeto, é possível compreender a aprendizagem humana em determinada atividade; e essa compreensão possibilitaria a proposição de metodologias mais eficientes, pois, para dizer como e o que se deve ensinar, precisamos, antes de mais nada, saber como acontece o processo de aprendizagem.

A ideia de "estádio", em epistemologia genética, relaciona-se a "degraus" de equilíbrio alcançados estruturalmente ao longo do desenvolvimento intelectual do sujeito. Piaget (1978; 1980) e Piaget e Inhelder (1999) distinguem, no desenvolvimento da lógica na criança e no adolescente, três estádios principais (sensório-motor, concreto e formal), sendo o segundo precedido por um longo período preparatório (pré-operatório). Esses estádios foram minuciosamente detalhados em um quadro específico para as operações intelectuais e possuem uma continuidade do ponto de vista orgânico, a partir do nascimento, com o reflexo inicial de sugar o seio da mãe, e não apresentam cortes naturais bem nítidos. Aliás, o caráter integrativo dos estádios do desenvolvimento é justamente uma das suas características. As estruturas construídas em um determinado momento pelo sujeito tornam-se parte integrante das estruturas posteriores. Ainda assim, os estádios do desenvolvimento não se caracterizam por uma justaposição de propriedades diferentes, umas sobre as outras, mas por uma estrutura de conjunto. Essa estrutura será própria para cada período do desenvolvimento.

O período de preparação e de organização das operações concretas de classes, relações e número se estende por cerca dos 2 anos até 11-12 anos de idade e está dividido em dois subperíodos: o da preparação funcional das operações (pré-operatório) e o da estruturação operatória propriamente dita (operatório-concreto). Por volta de 2-3 anos até cerca dos 4 anos de idade, a criança encontra-se no subperíodo do aparecimento da função simbólica em diferentes formas: imitação diferida, jogo simbólico, desenho, imagem mental e evocação verbal, além do início da interiorização dos esquemas de ação em representação. Com o surgimento da linguagem, as condutas da criança são profundamente modificadas. Por ser o momento do início da representação, a criança encontra dificuldades de pensar o espaço que não está próximo e o tempo não presente dos esquemas de objeto, espaço, tempo e causalidade já utilizados na ação efetiva (Piaget, 1978; 2006). As primeiras estruturas representativas que se revelam nesse nível, por volta dos 4-5 anos de idade, aparecem senão através de muitos questionamentos sobre a realidade (Piaget, 1999). Nesse momento, a criança ainda não é totalmente capaz de conservar conjuntos e quantidades, faz afirmações sem demonstrações, também não 
define os conceitos que emprega, limitando-se a justificar os objetos pelo uso: "isso é para..." (Piaget, 1980). No período pré-operatório, a criança não consegue definir o que é uma casa, por exemplo; ela consegue dizer apenas que uma casa é para morar, para dormir, etc. Nesse momento, as intuições elementares da criança são apenas esquemas perceptivos e de ação, ou senso-motores, mas transpostos ou interiorizados como representações. Até cerca de 7 anos, a criança permanece pré-lógica e suplementa a lógica pelo mecanismo da intuição. É uma simples interiorização das percepções e dos movimentos sob a forma de imagens representativas e de "experiências mentais" que prolongam os esquemas senso-motores sem coordenação propriamente racional. Por volta dos 6 até 7-8 anos de idade, a criança já está quase atingindo o nível de "fechamento" da estrutura do período com a construção da noção de conservação e relacionando os estados e as transformações dos objetos. Até atingir o nível de equilíbrio dessa estrutura, existe a ação e a representação mental dessa ação, mas não existe operação, que pressupõe a reversibilidade da ação. Como o próprio nome do período diz - "pré-operatório" -, não temos operação, porque não existe ainda a noção de conservação e, com esta ausência, a reversibilidade fica prejudicada. Assim, no período pré-operatório, momento em que se encontram os sujeitos investigados, existe uma inteligência que desempenha um papel importantíssimo, pois prolonga a inteligência sensório-motora do período pré-verbal e prepara as noções que se desenvolverão até a idade adulta.

\section{Materiais e métodos}

A metodologia, bem como os experimentos propostos, foi aplicada e aperfeiçoada a partir de um estudo piloto realizado anteriormente (Cabral; Aragón; Simões, 2021). Para a investigação dos processos cognitivos envolvidos na atividade de programação com crianças, foi aplicada uma entrevista, gravada em vídeo dividida em duas etapas: na primeira, foram realizadas provas cognitivas baseadas no método clínico-piagetiano para a verificação do estádio do desenvolvimento intelectual de cada sujeito; na segunda etapa, os sujeitos deveriam resolver problemas, chamados de experimentos, construindo o algoritmo para fazer movimentar um robô com o material Kids First Coding \& Robotics. A entrevista completa aconteceu em um único encontro, foi gravada em vídeo e analisada com auxílio do software de análise qualitativa MAXQDA2020®.

A abordagem escolhida para esta investigação é a pesquisa qualitativa, que busca obter dados descritivos através do contato direto do pesquisador com o objeto de estudo. A escolha por esse tipo de abordagem justifica-se na medida em que somente ela possibilita a análise do percurso cognitivo de cada sujeito durante a atividade de programação. A abordagem qualitativa na perspectiva do estudo de caso (Yin, 2016), com referência nos estudos de Inhelder et al. (1996), buscará analisar o progresso cognitivo macrogenético proposto por Piaget, apoiado em análises detalhadas das condutas dos sujeitos (microgênese), pois elas evidenciam características do processo interativo entre o sujeito e o objeto do conhecimento.

Para participar do estudo, os sujeitos deveriam ter vínculo escolar e proximidade com uma ou mais tecnologias digitais (celular, tablet, computador, notebook, brinquedos tecnológicos, etc.). As entrevistas foram realizadas individualmente. Os pais/responsáveis responderam a um questionário sobre os hábitos da criança com relação ao uso de tecnologias digitais, assinaram o Termo de Consentimento Livre e Esclarecido (TCLE) e as crianças o Termo de Assentimento Livre e Esclarecido (TALE). A pesquisa está registrada no Comissão Nacional de Ética em Pesquisa (CONEP). 
Com base nos estádios do desenvolvimento cognitivo propostos por Piaget, os sujeitos foram divididos em três grupos: dos 4-6, dos 7-9 e 10-12 anos de idade. Apresentaremos, aqui, os resultados encontrados no primeiro grupo de sujeitos analisados (pré-operatório).

As entrevistas, baseadas no método clínico-piagetiano (Carraher, 1998; Delval, 2002), foram realizadas com sete crianças de 4 até 6 anos de idade. Sabemos que, de acordo com a epistemologia genética de Jean Piaget, somente a idade cronológica não garante o desenvolvimento das estruturas lógicas, que pode variar bastante de acordo com o contexto social de inserção de cada indivíduo. Assim, na Etapa 1 da entrevista, para avaliar o estádio do desenvolvimento intelectual, bem como o desenvolvimento das estruturas lógicas elementares de classificação e de seriação (Piaget; Inhelder, 1971) e as noções iniciais de objeto, causalidade e espaço, foram realizadas nove provas cognitivas selecionadas diretamente das obras de Piaget. São elas: 1. Conservação de quantidades físicas e correspondência termo a termo com uso de fichas (Piaget, 1975); 2. Conservação de quantidades físicas e massa com uso de massa de modelar (Piaget, 1975); 3. Conservação de quantidades físicas com o transvasamento de líquido (Piaget, 1975); 4. Inclusão de classes com o uso da categoria flores (Piaget; Inhelder, 1971); 5. Inclusão de classes com o uso de categorias frutos (Piaget; Inhelder, 1971); 6. Seriação de bastonetes (Piaget; Inhelder, 1971); 7. Causalidade com o uso de perguntas (Piaget, 1999); 8. Espaço/horizontalidade através da prova do desenho da linha da água e do "barquinho" (Piaget; Inhelder, 1993); 9. Espaço/horizontalidade através da prova das árvores na montanha (Piaget; Inhelder, 1993).

$\mathrm{Na}$ Etapa 2 da entrevista, foram propostos onze experimentos construídos com a ferramenta Kids First Coding \& Robotics produzido pela empresa Thames e Kosmos, comercializado como brinquedo tecnológico para a atividade de programação. Na caixa do produto, existe a indicação de faixa etária para uso (4-8 anos de idade). O brinquedo recebeu prêmios como Winner Parents' Choice Gold Award no ano de 2018 e Toy of the Year em 2019 nos Estados Unidos. O material não é vendido no Brasil e foi importado através da empresa Amazon. Para a construção do algoritmo de programação com esse material, não é necessário um dispositivo com tela. Os comandos são simbolizados por cartas coloridas que são encaixadas em uma grade, iniciando com a carta "start" e finalizando com uma carta vermelha que indica o fim da programação. À medida que o robô passa pelas cartas contendo símbolos, um scanner óptico OID, na parte inferior do robô, lê os cartões de código, um por um, e memoriza o programa. Com o algoritmo memorizado, é necessário colocar o robô para percorrer os mapas executando a programação. É possível programar o robô para movimentar em diferentes direções, ativar uma engrenagem de saída, acender um LED, reproduzir sons e responder a diferentes placas de função. As peças plásticas que integram o kit possibilitam a criação de objetos simples que se encaixam à plataforma. A escolha desse material, que não utiliza tablet, smartphone ou computador para a programação, justifica-se uma vez que existe um processo de aprendizagem relacionado ao uso desses dispositivos, como nos mostrou Fagundes (1986), que não é o foco desta investigação e poderia interferir nos resultados obtidos.

No início da Etapa 2 da entrevista, é questionado para o sujeito o que é um robô e como ele se movimenta. Com esses questionamentos, objetiva-se recolher as representações iniciais do sujeito acerca do objeto. É realizado então um "jogo de memória", no qual é apresentada uma sequência de cartas para memorização em 10 segundos, contendo comandos simples (para frente $\rightarrow$, para trás $\leftarrow$, vire à direita $\downarrow$ ou vire à esquerda $\uparrow$ ). Em seguida, é proposto que o sujeito repita a sequência na grade de programação. Inicialmente, é apresentada uma sequência com três cartas $(\rightarrow \rightarrow \downarrow)$, depois 
com quatro cartas $(\rightarrow \downarrow \rightarrow \uparrow)$, cinco cartas $(\rightarrow \uparrow \rightarrow \rightarrow \downarrow)$ e, finalmente, seis cartas $(\rightarrow \rightarrow$ $\downarrow \leftarrow \leftarrow \uparrow)$. Assim, pretende-se observar a quantidade de comandos em sequência que é possível ser memorizada pelos sujeitos. Também se trata de uma oportunidade para o sujeito experimentar a grade onde devem ser encaixadas as cartas para a construção do algoritmo. As cartas possuem um encaixe específico, o que não possibilita a colocação aleatória das cartas na grade.

Os experimentos criados foram divididos em dois grupos. O Grupo 1 (G1) é composto por seis experimentos (E1, E2, E3, E4, E5 e E6) e utiliza um robô semelhante ao formato de um rato, construído com peças plásticas, e três mapas diferentes. Já o Grupo 2 (G2) é constituído de outros cinco experimentos (E7, E8, E9, E10 e E11) com um robô semelhante a um jogador de futebol e utiliza um mapa com quatro modificações, totalizando onze experimentos. No primeiro experimento do Grupo 1 (G1[E1]), é apresentado para ao sujeito um rato encaixado à plataforma da ferramenta Kids First Coding \& Robotics e uma sequência de seis quadrados dispostos em linha reta que formam um mapa que deverá ser percorrido pelo robô. A primeira programação deve fazer com que o robô chegue até o último quadrado do mapa em linha reta, onde supostamente foi "esquecido" um queijo no chão. O queijo é representado por peças plásticas amarelas. A conversa com a criança adapta-se conforme a faixa etária. No G1[E2], é solicitado que o sujeito construa uma programação para que o ratinho, saindo do ponto inicial (start), vá até o último quadrado onde está o "queijo esquecido" e retorne ao ponto inicial. No experimento G1[E3], o mapa é alterado para seis quadrados que compõem uma reta com uma curva. É solicitado que, saindo do ponto inicial, o sujeito programe o robô para ir até o ponto final onde está o queijo esquecido. Em G1[E4], é solicitado que o robô vá e volte pelo mesmo caminho com reta e curva. No G1[E5], é disponibilizado um novo mapa, também com seis quadrados, agora em zigue-zague. $\mathrm{O}$ sujeito deverá realizar uma programação que leve o robô até o ponto final do mapa onde está o "queijo esquecido". No experimento G1[E6], é solicitado que o sujeito construa uma programação para sair do ponto inicial e retornar ao ponto inicial ${ }^{1}$.

No início da Etapa 2 da entrevista, é solicitado que o sujeito escolha um nome para o(a) robô rato(a). O mesmo acontece para o(a) jogador(a) de futebol. Também é apresentada uma caixa com as cartas de comandos e suas funcionalidades, a carta de início e de fim da programação. As cartas foram divididas em uma caixa com divisórias para facilitar a visualização do sujeito, pois a necessidade dessa divisão foi percebida ainda antes da execução do projeto-piloto (Cabral; Aragón; Simões, 2021). A divisão das cartas

\footnotetext{
${ }^{1}$ Os sujeitos analisados no presente estudo não avançaram suficientemente para resolver os experimentos do Grupo 2, com um objeto semelhante a um jogador de futebol anexado à plataforma e um mapa do "campo de futebol" composto por dez quadrados. No G2[E7], é solicitado que o sujeito construa uma programação que faça com que o jogador de futebol robô alcance a goleira. No G2[E8], é solicitado que o sujeito programe o robô para se deslocar novamente até a goleira e "chute" a bola que é lançada ao gol através do movimento de uma engrenagem, também programável, a qual é acionada quando o sensor detecta a carta com a função "estrela azul", adicionada ao mapa inicial. No G2[E9], é solicitado que programe o robô para se deslocar até a goleira e "chute" a bola; mas quando o robô encontrar um adversário no percurso, é necessário fazer um movimento de "drible". O movimento deve ser incluído na programação através das cartas com a condicional IF - DO. O movimento é realizado quando o sensor detecta figuras no mapa onde estão os jogadores "adversários". No G2[E10], é solicitado que o sujeito construa o algoritmo para que o robô se desloque até a goleira e "chute" a bola, mas, agora, quando o robô encontrar um ou outro adversário no percurso, é necessário fazer o movimento de "drible". O movimento é incluído na programação através das cartas com condicionais IF - DO e operador lógico OR. No último experimento (G2[E11]), é solicitado que o sujeito programe o robô para se deslocar até a goleira e "chute" a bola, mas quando o robô encontrar um e também o outro adversário no percurso, é necessário fazer um movimento de drible. Enquanto isso, um efeito luminoso ou sonoro é executado. O movimento é incluído na programação através das condicionais IF - DO - ELSE e operador lógico AND.
} 
para programação realizada é a seguinte: carta de início da programação (start); carta de fim da programação (carta vermelha); cartas com movimento para frente $(\rightarrow)$ e cartas com movimento para trás $(\leftarrow)$; cartas com movimento de virar à direita $(\downarrow)$ e virar à esquerda $(\uparrow)$; cartas com giro da engrenagem no sentido horário, anti-horário, pausa da engrenagem e pausa do movimento; cartas com efeitos sonoros; cartas com efeitos luminosos; cartas com números de 1 até 9; cartas com loop; cartas com função; cartas com condicionais (IF, DO, ELSE) e operadores lógicos (AND, OR).

\section{Resultados e Discussões}

As provas cognitivas aplicadas na Etapa 1 da entrevista, conforme o método clínico-piagetiano (Carraher, 1998; Delval, 2002) com sete crianças de 4 até 6 anos de idade, evidenciaram que o grupo se encontra no subperíodo das operações préoperatórias. Sabemos que, de acordo com a epistemologia genética de Jean Piaget, somente a idade cronológica não garante o desenvolvimento das estruturas lógicas, justifica-se a necessidade da realização das provas cognitivas que evidenciaram, além da estrutura cognitiva, as diferenças individuais no desenvolvimento das noções investigadas, ou decalagens horizontais (Piaget, 1978) e como isso influencia a resolução dos experimentos para a construção do algoritmo de programação.

A representação inicial descrita pelos sete sujeitos investigados sobre "o que é um robô" sugere que a imagem mental acionada se relaciona, por unanimidade, com objetos já visualizados por eles, que sugerem a figura de um humanoide, por exemplo: É todo azul e "banco" (branco), só que a cara é azul e o resto todo "banco". É azul forte. (S5_1: 332). As descrições citam cabelos, olhos, pernas e braços, por exemplo: E também ele tem uma cabeça igual a nossa. [...] E tem um braço e uma perna (S4_1: 339). Além disso, também se relacionam com objetos visualizados anteriormente na televisão ou na loja de brinquedos, por exemplo: É um desenho que eu gosto de ver. (S6_2: 130). Ou ainda: Só vi aqueles na rua, de brinquedo. (S7_1: 253). Com relação ao questionamento sobre "como um robô se movimenta", os sujeitos citaram fios, motores, pilhas, baterias e botões como necessários para a movimentação do robô, ou seja, mais uma vez aquilo que os sujeitos observam da sua própria experiência com o real através da experiência. Nenhum sujeito citou a questão da programação como responsável pela movimentação do robô. As representações infantis coletadas aqui sobre "o que é um robô" e "como um robô se movimenta" evidenciam a relação da representação infantil com o subestágio préoperatório, em que se inicia esse processo de construção, e a criança encontra dificuldade em pensar em tudo aquilo que não está próximo do tempo presente. Seus interesses, brincadeiras, desenhos e representações fazem referência àquilo que existe no seu mundo de brinquedos, desenhos animados e filmes. Em suma, o pensamento da criança tem toda a aparência de um cuidado exclusivo com o realismo (Piaget, 2005).

Os resultados encontrados no "jogo de memória", no qual são apresentadas quatro sequências crescentes de comandos simples para a memorização, demonstram que os sete investigados encontraram dificuldades para memorizar os algoritmos. Um dos sujeitos do grupo de 4-6 anos memorizou três sequências, um sujeito memorizou duas e um sujeito somente uma sequência. Os outros quatro sujeitos não conseguiram repetir, na grade de programação, a sequência de códigos. Piaget e Inhelder (1968) nos dizem que a memória é uma das funções cognitivas, sendo a inteligência a função superior, e que a construção e a reconstrução de memórias se relacionam diretamente com a construção das estruturas operatórias. Através do desenvolvimento cognitivo, acredita-se, então, que será possível observar uma melhora significativa nos resultados do "jogo de memória" nos próximos 
grupos de indivíduos a serem investigados (7-9 e 10-12 anos). Contudo, o principal indicador que podemos inferir desse resultado é que o trabalho com atividade de programação baseado em sequências de comandos memorizados não se mostra eficiente, uma vez que os sujeitos não conseguem saber qual o comando foi enviado para a execução pelo objeto. Dessa maneira, se confirma a escolha pela ferramenta Kids First Coding \& Robotics para o presente estudo, pois se utiliza de cartas nas quais é possível a visualização concreta do comando a ser executado pelo objeto.

Com a análise refinada das condutas dos sujeitos (Inhelder et al., 1996) ao longo de nove provas cognitivas, observou-se que as noções de classificação, seriação, objeto, causalidade e espaço não se desenvolveram de uma mesma maneira em todos os sujeitos investigados. Os indivíduos demonstraram que uma noção pode se apresentar em estado ainda bastante inicial e outra em processo quase consolidado de construção, mas ainda sem o fechamento estrutural necessário, que marca a entrada no estágio seguinte. Todos os sujeitos investigados demonstraram estar em diferentes momentos: no subperíodo préoperatório do desenvolvimento cognitivo com a função simbólica em desenvolvimento, a representação emergente e sem a consolidação da reversibilidade. Logo, será necessário um percurso para que a estrutura cognitiva se consolide no subperíodo das operações préoperatórias e se abra, em seguida, para o estágio seguinte: o operatório-concreto.

A entrevista do Sujeito 5 (S5), que possui 5 anos e 9 meses de idade (05a.09m.), evidenciou que sua estrutura cognitiva está em estado inicial de desenvolvimento no subperíodo pré-operatório, com várias noções ainda não consolidadas, tais como conservação, seriação e inclusão. Na Etapa 2 da entrevista, S5 não conseguiu avançar para o segundo experimento. Utilizou o tempo total de 01:12:23 para realizar a entrevista e ficou apenas na resolução do G1[E1]. Iniciou a solução do experimento completando a grade de programação com cartas de comando para frente e testou o robô que escapou do limite do mapa. S5 foi relembrando da regra de uma carta de programação para cada movimento executado no mapa, mas tal informação não foi assimilada pelo sujeito, que realizou pequenas alterações no algoritmo de dez cartas e realizou quatro tentativas de alteração. No quarto algoritmo, S5 testou o movimento do robô mais quatro vezes (gravava a programação e executava o movimento no mapa) sem realizar nenhuma alteração no algoritmo, mas parecia esperar um movimento diferente do robô. Ao final dos testes, foi demostrado, na grade de programação, como deveria ser a programação para levar o robô até o final do mapa, mas S5 observou o algoritmo e completou a grade de programação com cartas sem abandonar sua hipótese inicial. Assim como S5, S7 (05a.03m.) também trabalhou somente no experimento G1[E1] sem alcançar uma solução para o problema e também completou a grade de programação com cartas. Ao observar que o robô escapou do limite do mapa, a seguinte conversa se iniciou: PESQ.: Passou, né? Como é que faz pra ele parar bem aqui? Tu sabes? Tu que estás dando os comandos pra ele aí. Quantas cartas eu tenho que colocar aí (na grade) pra ele parar bem aqui? S7: Hum. Tem que colocar o queijo ali ó (fora do mapa). PESQ. Tem que colocar o queijo lá? Mas eu queria que o queijo ficasse aqui e que ele parasse bem aqui, como faz? S7: Só que ele não consegue parar. PESQ. Por quê? S7: Porque os ratos, eles são muito violentos. A resposta do sujeito, recorrendo à fabulação, é uma espécie de fuga que a criança se utiliza como resposta, pois, naquele momento, o questionamento não faz nenhum sentido para ela e a resposta com fabulação é uma espécie de "não importismo" (Piaget, 2005).

Já o Sujeito 3 (S3-05a.07m.) demonstrou, na Etapa 1 da entrevista, possuir a noção de conservação em processo de consolidação, enquanto a noção de inclusão ainda era inicial, pois conseguiu perceber as transformações realizadas em um objeto a sua frente, mas não incluiu, por exemplo, objetos em uma mesma categoria. A classificação e a 
seriação são estruturas lógicas elementares do pensamento (Piaget; Inhelder, 1971), do qual faz parte a noção de inclusão, porém a consolidação dessas estruturas lógicas só acontecerá no final do estágio operatório-concreto, por isso as diferenças encontradas nas provas cognitivas dos sujeitos investigados. Na Etapa 2 da entrevista, S3 completou a grade de programação com cartas, sem estabelecer a relação termo a termo necessária para solução do problema (assim como S5 e S7) e executa a programação que faz com que o robô exceda o limite do mapa. Depois de observar o movimento executado pelo robô e de ser relembrado da regra de uma carta de programação para cada movimento executado no mapa, S3 reformulou seu algoritmo na grade de programação e construiu uma nova solução que resolveu o problema $(\rightarrow \rightarrow \rightarrow \rightarrow \rightarrow)$. Para S3, a observação do movimento do robô juntamente com a recomendação foi suficiente para chegar à solução. A mesma condição não foi suficiente para S5 e S7. No caso de S3, evidencia-se a importância dos dados observados através da experiência concreta para a coordenação das ações pelo sujeito. No G1[E2], o S3 construiu três soluções diferentes de algoritmo que não atingiram o êxito. Ora colocava as cartas todas para a frente, ora colocava todas para trás, sem encontrar solução para o problema, evidenciando a não conservação, tampouco a inclusão de classes que também não foram evidenciadas nas provas cognitivas. Em determinado momento, S3 disse não saber como resolver o problema, mas pediu para fazer o experimento seguinte. O experimento G1 [E3] foi solucionado por S3 com duas tentativas, mas importante ressaltar que não envolvia a noção de reversibilidade como exigido no experimento anterior. No G1[E4], S3, mais uma vez, construiu um algoritmo sem obter êxito, pois este envolvia a reversibilidade do movimento e, consequentemente, do próprio pensamento. Ainda assim, pediu para avançar para o experimento seguinte, mas no G1[E5] construiu um algoritmo que não obteve êxito e pediu para finalizar a entrevista, utilizando o tempo total de 01:08:40.

O Sujeito 1 (S1) com 6 anos e 6 meses (06a.06m.) demonstrou estar bem mais avançado no processo de fechamento da estrutura do subestágio operatório-concreto em relação aos demais sujeitos do grupo; contudo, na prova cognitiva de conservação de quantidades físicas com uso de massa de modelar (Piaget, 1975), hesitou em admitir a conservação do objeto após transformações ${ }^{2}$. Com isso, queremos sublinhar a importância do conceito de decalagem horizontal para um bom entendimento da teoria dos estágios do desenvolvimento. Nos diz Piaget (1978) que as decalagens resultam das resistências do objeto ao ser assimilado pelo sujeito e que o desenvolvimento de uma noção poderá atingir um determinado nível ao contrário de outras; ou seja, o desenvolvimento dessas noções não é um processo linear que ocorre de maneira uniforme, tampouco ocorre da mesma maneira em diferentes sujeitos, pois tudo dependerá do percurso cognitivo individual de cada sujeito para o desenvolvimento das mesmas. S1 utilizou na Etapa 1 (provas cognitivas) o tempo de 00:30:23 e, na Etapa 2 (resolução dos experimentos), o tempo de 00:28:21, totalizando 00:58:44 de tempo de entrevista. Resolveu o experimento G1[E1] com apenas uma tentativa, relacionando a quantidade de cartas necessárias para a movimentação do robô com a quantidade de quadrados no mapa (relação termo a termo) e construiu um algoritmo que resolvia o problema $(\rightarrow \rightarrow \rightarrow \rightarrow \rightarrow)$. Observou-se que o sujeito contou a quantidade de quadrados no mapa e colocou a quantidade de cartas correspondentes na grade de programação, evidenciando a noção de relação termo a termo explorada na prova cognitiva de conservação de quantidades físicas e correspondência

\footnotetext{
${ }^{2}$ Em síntese, essa prova parte do estabelecimento de uma relação entre duas quantidades físicas $(A=B)$ organizadas espacialmente de maneira que as relações conceituais e perceptuais são iguais e parecem iguais. No momento seguinte, a igualdade das quantidades não pode mais ser constatada simplesmente com base na percepção, pois a disposição espacial das quantidades a serem comparadas é diferente (A e B são iguais, mas parecem diferentes).
} 
termo a termo com uso de fichas (Piaget, 1975). Aliás, S1 demonstrou, nas provas cognitivas, que construiu várias das noções investigadas e que está em processo de consolidação da reversibilidade. Por esse motivo, obteve êxito no experimento G1[E2], modificando o algoritmo inicial, mantendo as cinco cartas que havia colocado na grade de programação e acrescentando cinco cartas para fazer o robô retornar para a base. Aqui, observou-se que S1 também consolidou a noção de conservação de quantidades, pois, diferentemente de outros sujeitos investigados, não retirou todas as cartas da grade de programação para reiniciar a construção do algoritmo. Também foi observado que S1 representou e operou mentalmente o movimento de reversibilidade (ida e volta) que o robô deveria fazer no mapa; e, por isso, para ele, bastou acrescentar cinco cartas para resolver o experimento. No G1[E3], foi acrescentada uma curva ao mapa onde o robô se desloca, S1 teve uma pouco mais de dificuldade e precisou reformular suas hipóteses para atingir o êxito. Na primeira tentativa, S1 não considerou a diminuição de um dos quadrados do mapa e manteve cinco cartas na programação acrescentando uma curva. Ao iniciar o robô, o sujeito reagiu da seguinte maneira: Vai, vai e aqui dobra tá? (falando alegremente com o robô) Vai! (o robô sai para fora do mapa) Ué, como assim? (modificou o algoritmo) (S1_2: 117). S1 observou que precisava diminuir uma carta na programação e evidenciou, mais uma vez, a necessidade dos dados observáveis para os sujeitos, especialmente no subperíodo operatório-concreto, pois, a partir deles, conseguem coordenar suas ações e reformular a solução. $\mathrm{O}$ fato de diminuir uma carta de programação ao ser retirado um quadrado no mapa só foi percebido por S1 ao observar o movimento executado pelo robô. Daí a importância da realização das atividades pelo sujeito e sua consequente reflexão a partir dos dados observáveis. Para resolver o G1[E4], S1 utilizou seis algoritmos diferentes. Na sexta tentativa, atingiu o êxito na solução do problema, mas sua reação de surpresa evidenciou que foi desencadeada ao acaso: (Grava a programação e coloca o robô no mapa que inicia o movimento. No quarto giro executado pelo robô, ele diz surpreso) Ahhhh. (O robô gira para o lado contrário que desejava, mesmo assim retorna para a base de ré e estaciona corretamente no início do mapa) Mas saiu! Olha isso! Olha isso! Olha! Tá aqui! Mas pelo menos foi. (S1_2: 224) Depois disso, deu-se por satisfeito e pediu para encerrar a entrevista.

\section{Conclusão}

O trabalho com atividade de programação com crianças de pouca idade, como as que foram investigadas no presente estudo, mostrou-se uma atividade possível, sobretudo quando está vinculada à movimentação de um objeto concreto, como acontece em robótica educacional. Além disso, a visualização concreta da sequência de comandos no algoritmo de programação possibilita a verificação dos observáveis e a coordenação das ações físicas (na reorganização dos comandos nas cartas) e mentais (na reorganização das estratégias de resolução de problemas) da criança.

O desenvolvimento progressivo da estrutura cognitiva do sujeito dependerá também do desenvolvimento de uma série de noções que compõem essa estrutura, tais como as noções de classificação, seriação, objeto, causalidade e espaço investigadas aqui. Essas noções estão envolvidas nas capacidades cognitivas das crianças para que alcancem o êxito na elaboração de um algoritmo de programação que resolva um experimento/problema. Não se desenvolvem de maneira igualitária em todos os sujeitos, mas são necessárias para a resolução de problemas como os propostos nos experimentos desta investigação. 
Com isso, não queremos dizer que a atividade de programação e de robótica educacional não deva ser realizada por aqueles sujeitos que ainda não desenvolveram tais noções, mas ao contrário: que a atividade de programação e robótica educacional com crianças de pouca idade poderá provocar, na medida da estrutura cognitiva do sujeito, o desenvolvimento dessas capacidades.

\section{Agradecimentos}

O presente trabalho foi realizado com apoio da Coordenação de Aperfeiçoamento de Pessoal de Nível Superior - Brasil (CAPES) - Código de Financiamento 001.

\section{Referências}

CABRAL, C. P. Robótica Educacional e Resolução de Problemas: uma abordagem microgenética da construção do conhecimento. Dissertação (Mestrado em Educação) Faculdade de Educação, Universidade Federal do Rio Grande do Sul, Porto Alegre, 2010.

CABRAL, C. P.; ARAGÓN, R.; SIMÕES, A. S. Desenvolvimento cognitivo e a atividade de programação com crianças. Revista Pesquisa Qualitativa, v. 9, n. 20, p. 114-142, 2021.

CARRAHER, T. N. O Método Clínico: usando os exames de Piaget. 5. ed. São Paulo: Cortez, 1998.

DELVAL, J. Introdução à Prática do Método Clínico: descobrindo o pensamento das crianças. Porto Alegre: Artmed, 2002.

FAGUNDES, L. C. Psicogênese das condutas cognitivas da criança em interação com o mundo do computador. Tese (Doutorado em Psicologia) - Instituto de Psicologia, Universidade de São Paulo, São Paulo, 1986.

INHELDER, B. et al. $\mathbf{O}$ desenrolar das descobertas da criança: um estudo sobre as microgêneses cognitivas. Porto Alegre: Artes Médicas, 1996.

PIAGET, J. A Linguagem e o Pensamento da Criança. 7. ed. São Paulo: Martins Fontes, 1999.

PIAGET, J. Seis estudos de Psicologia. Rio de Janeiro: Forense Universitária, 1980.

PIAGET, J. O nascimento da inteligência na criança. 2. ed. Rio de Janeiro: Zahar, 1975. PIAGET, J. A representação do mundo na criança. 5. ed. São Paulo: Ideias \& Letras, 2005.

PIAGET, J. A Construção do Real na Criança. São Paulo: Ática, 2006.

PIAGET, J. Problemas de Psicologia Genética. In: PIAGET, J. A epistemologia genética: sabedoria e ilusões da filosofia; problemas de psicologia genética. São Paulo: Abril Cultural, 1978. p. 209-204.

PIAGET, J.; INHELDER, B. A representação do Espaço na Criança. Porto Alegre: Artes Médicas, 1993.

PIAGET, J.; INHELDER, B. A Psicologia da Criança. 16. ed. Rio de Janeiro: Bertrand Brasil, 1999.

PIAGET, J.; INHELDER, B. Gênese das Estruturas Lógicas Elementares. Rio de Janeiro: Zahar, 1971.

PIAGET, J.; INHELDER, B. Memória e Inteligência. Brasília: Ed. UNB, 1968. YIN, R. K. Pesquisa Qualitativa do início ao fim. Porto Alegre: Penso, 2016. 